\title{
Gas generation by coal matter in contemporary conditions
}

\author{
Kostiantyn Bezruchko ${ }^{1, *}$, Oleksandr Burchak $^{1}$, and Oleksandr Balalaiev ${ }^{1}$ \\ ${ }^{1}$ Institute of Geotechnical Mechanics named by N. Poljakov of National Academy of Sciences of \\ Ukraine, 49005, Dnipro, Simferopolska Str., 2a, Ukraine
}

\begin{abstract}
A new approach for the study of processes at the atomicmolecular level occurring in the current situation in fossil carbonized organics was proposed. A new phenomenological model of physicochemical transformations in a metastable coal substance with the emission of fluids has been developed. The proposed physic/chemical model is based on the genetic connection of coal methane with fossil organic matter and determines the conditions for the activation of structural transformations in coalmines. This model describes the possible options for the coal/gas system development in the current situation. The accumulation of thermal and mechanical energy by coal in the form of structural stresses in an amount, sufficient to activate free-radical reactions, was experimentally established. In the undisturbed coalrock massif the processes of the coal molecular structure transformation have the relaxation character. The result of relaxation of the accumulated energy in the conditions of a gas-saturated coalrock massif is the methane generation by coal. Gas generation in the process of coalification, in its essence, is the energy response of the system to the action of external geomechanical options (temperature and pressure), by the way of releasing the accumulated additional energy with the emission of gaseous products and the destruction of the solid phase in the organic matter of the coal.
\end{abstract}

\section{Introduction}

The natural gas content of coal deposits is mainly formed as a result of irreversible structural transformations of fossil carbonized organic matter. The key factors causing these processes are temperature and gravitational pressure during the immersion of sediments. Under the action of external factors in the coal substance, transformations with the emission of stable low-molecular weight compounds are occurred, primarily methane and its homologues. Simple calculations and measurement of the contemporary gas content of Donbas coal seams show that most of the fluids $(\approx 90 \%)$, and in particular, methane, which were formed during sedimentation, migrated during the inversion period to the ground surface on the cracks and fractures. However, the amount of gas entering of the mine workings during the coal and gas outbursts or suflyar emissions several times (sometimes by an order of magnitude) exceeds the natural gas content of coal and their maximum

\footnotetext{
*Corresponding author: gvrvg@meta.ua
} 
sorption capacity. The appearance of such significant volumes of gas in modern mines at relatively constant rock pressure and temperature has not yet found a convincing explanation. The appearance of such significant volumes of gas in modern mines at relatively constant rock pressure and temperature has not yet found a convincing explanation. (sometimes by an order of magnitude) exceeds the natural gas content of coal and their maximum sorption capacity. The emergence of such significant volumes of gas in contemporary mines at relatively constant rock pressure and temperature has not yet found its convincing explanation.

Practical experience in the development of methan-coal deposits and the results of scientific research indicate the imperfection of the existing concepts of the coal-gas system and the conditions of its formation, which makes it relevant to study the processes at the atomic-molecular level of a coal substance and to develop a physicochemical model of structural transformations in coal.

The purpose of the paper is to study the processes occurring in organic matter at the atomic-molecular level in modern conditions and to develop a physicochemical model of structural transformations of organic matter.

\section{Methodology}

Gas generation in the process of coalification is the result of complex physicochemical transformations in the coal substance at the macro-, micro-, nano- and atomic-molecular levels of the structural hierarchy in the coal seam [1]. However, the complexity, diversity and metastability of coal structures lead to the fact that the study of such transformations by classical empirical-theoretical methods is difficult.

In the research of such multi-faceted natural objects as coal, the dynamic approach is the most effective, as a way to study objects and phenomena in the process of their change. Such method allows you to identify patterns, velocity and direction of transformation of the coal substance under the action of external forces. As well as to determine the types and sources of energy, due to which these transformations can be occurred.

The methodology for studying structural transformations in coal is based on the simulation of processes according to physical research methods. For this, we used contemporary spectroscopic methods: electron paramagnetic resonance (EPR), nuclear magnetic resonance (NMR) and infrared spectroscopy (IR), taking into account the petrographic classification and technical analysis. The usage of these methods made it possible to determine the features of the electronic structure in macromolecules of coal and its behavior when changing the baric and thermal conditions. To assess the influence of external factors on the molecular structure and energy state of fossil organic matter under laboratory environment.

For conducting structural research of carbon-containing organic matter, samples of subbituminous, bituminous coals and anthracite, selected at twenty-five mines of five geological-industrial areas of Donbas, were used. Total use is 197 samples from thirtyseven mine-seams, the excavated volume exceeded a thousand samples. Preparation of mine samples for laboratory research was carried out considering the properties of coal particles from various fractions, in the minimum required volume and by standard methods. Data processing, obtained using non-destructive physical methods for studying the structure of a substance was carried out, based on technical analysis, petrographic and geological studies. 


\section{Discussion of the outcomes}

Research of the structural transformations of coal substances under the influence of external force fields were performed in the laboratory environment. The effect of mechanical stress on the molecular structure of coal was studied by the Fourier-transform spectroscopy (FTIR) method. Due to the fact that the chemical composition and mechanical properties of coal macerals differ significantly, measurements were performed on vitrinite and inertinite concentrates.

Samples of coal were subjected to uniaxial compression on a hydraulic press $\left(10^{9} \mathrm{~Pa}\right)$. This value greatly exceeds the ultimate compressive strength for coal and the natural pressure in the reservoir.

Figure 1 shows FTIR fragments of coal before and after uniaxial compression, reduced to the baseline in the range of wave numbers $2810-3130 \mathrm{~cm}^{-1}$.

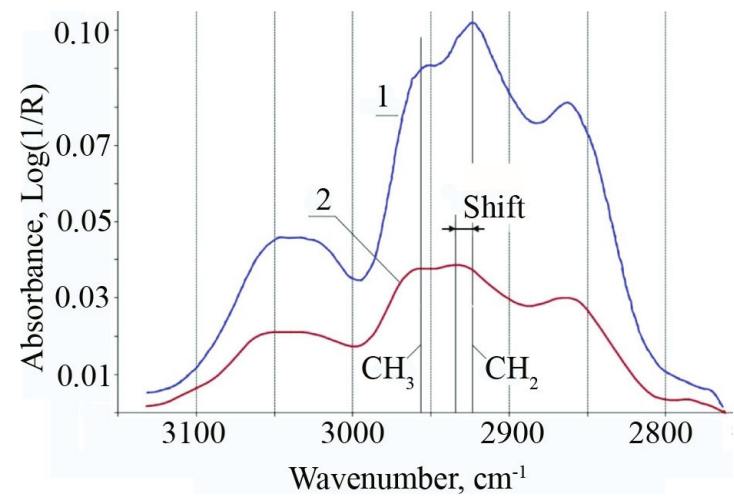

Fig. 1. FTIR of valence vibrations of $\mathrm{CH}$ groups of coal before (1) and after (2) uniaxial compression.

According to FTIR of the valence vibrations in the $\mathrm{CH}$ groups in the molecular structure of coal macerals, three indicators were determined. The obtained data are in the Table 1. Three indexes were calculated: the degree of the coal substance aromaticity $\left(D_{2920} / D_{2956}\right)$, the redistribution coefficient of hydrogen as the ratio of the areas of the model absorption peaks of $\mathrm{CH}_{3} / \mathrm{CH}_{2 \text { as }}$ symmetric valence vibrations in the aliphatic component of the coal substance and the absorption band shift of the valence vibrations in the $\mathrm{CH}_{2 \text { as }}$ group (at frequency of $\mathrm{D}_{2920}$ ).

Experiments have shown an increase in the degree of coal aromaticity after compression, which indicates about the structurization of the substance with the formation of cyclic hydrocarbons.

Redistribution of protons between the functional $\mathrm{CH}_{2}-\mathrm{CH}_{3}$ groups in the aliphatic component of the organic matter of coal has also been recorded. Under mechanical stress destruction of macromolecules of coal occurs in the form of splitting off the terminal methyl groups, stabilized by redistributed hydrogen. The migration of protons to finite groups is one of the mechanisms of methane generation by coal under the action of external force fields. The value of the hydrogen redistribution coefficient under mechanical load decreases in a metamorphism series for both microcomponents. This effect is associated with a decrease in the number of aliphatic fragments in the substance and a general decrease in the hydrogen content with increasing degree of carbonification.

The shift of the absorption band (frequency change of vibrations of interatomic bonds) characterizes the energy that a substance accumulates under a force load in the form of structural stresses. In this experiment, the maximum recorded shift of the absorption band was $12 \mathrm{~cm}^{-1}$ (m. Yuvileyna), which is $\approx 1.44 \mathrm{~J} / \mathrm{mol}$ in energy units, and this is only for the $\mathrm{CH}$ bond in the $\mathrm{CH}_{2}$ group. 
Tab. 1. The evaluation findings of the influence of mechanical pressure on the parameters of the molecular structure of the coal macerals substance (vitrinite concentrate).

\begin{tabular}{|c|c|c|c|c|c|}
\hline $\begin{array}{c}\text { Mine } \\
\text { (layer, } \\
\text { volatile content) }\end{array}$ & $\begin{array}{l}\text { Pressure, } \\
10^{9} \mathrm{~Pa}\end{array}$ & $\begin{array}{c}\text { Aromatic degree } \\
\text { Ar, rel. unit }\end{array}$ & $\begin{array}{c}\text { Coefficient of } \\
\text { hydrogenium } \\
\text { redistribution, } \\
\text { H, rel. unit }\end{array}$ & $\begin{array}{l}\text { The band of } \\
\text { shift, } \\
\mathrm{cm}^{-1}\end{array}$ & $\begin{array}{c}\text { Maximum } \\
\text { shift in a } \\
\text { diapason, } \\
\mathrm{cm}^{-1}\end{array}$ \\
\hline \multicolumn{6}{|c|}{ Vitrinite concentrate } \\
\hline \multirow{2}{*}{$\begin{array}{c}\text { Blahodatna }\left(c_{5}, V^{d a \mathrm{f}}=\right. \\
46.12 \%)\end{array}$} & 0 & $0.083 \pm 0.004$ & $23.50 \pm 1.60$ & \multirow{2}{*}{$9.46 \pm 0.79$} & \multirow{2}{*}{6.72} \\
\hline & 10 & $0.084 \pm 0.002$ & $29.62 \pm 5.03$ & & \\
\hline \multirow{2}{*}{$\begin{array}{c}\text { Yuvileina } \\
\left(c_{6}, V^{\text {daf }}=42.24 \%\right)\end{array}$} & 0 & $0.113 \pm 0.018$ & $15.27 \pm 0.79$ & \multirow{2}{*}{$10.63 \pm 1.85$} & \multirow{2}{*}{12.00} \\
\hline & 10 & $0.308 \pm 0.218$ & $15.12 \pm 0.31$ & & \\
\hline \multirow{2}{*}{$\begin{array}{l}\text { Krasnolymanska } \\
\left(l_{3}, V^{d a f}=31.9 \%\right)\end{array}$} & 0 & $0.165 \pm 0.014$ & $11.68 \pm 3.24$ & \multirow{2}{*}{$7.40 \pm 0.76$} & \multirow{2}{*}{4.08} \\
\hline & 10 & $0.171 \pm 0.017$ & $14.72 \pm 3.26$ & & \\
\hline \multirow{2}{*}{$\begin{array}{c}\text { Named after } \\
\text { O.F. Zasiadko } \\
\left(m_{3}, V^{d a f}=31.29 \%\right)\end{array}$} & 0 & $0.209 \pm 0.019$ & $10.76 \pm 1.91$ & \multirow{2}{*}{$6.92 \pm 0.22$} & \multirow{2}{*}{8.64} \\
\hline & 10 & $0.294 \pm 0.133$ & $12.79 \pm 0.85$ & & \\
\hline \multirow{2}{*}{$\begin{array}{l}\text { Krasnoarmiiska-Zah. } \\
\left(d_{4}, V^{d a f}=26.02 \%\right)\end{array}$} & 0 & $0.214 \pm 0.006$ & $9.91 \pm 0.05$ & \multirow{2}{*}{$4.83 \pm 1.30$} & \multirow{2}{*}{9.60} \\
\hline & 10 & $0.468 \pm 0.006$ & $9.85 \pm 0.51$ & & \\
\hline \multirow{2}{*}{$\begin{array}{c}\text { Yasynovska-Hlyboka } \\
\left(m_{3}, V^{\text {daf }}=19.6 \%\right)\end{array}$} & 0 & $0.278 \pm 0.003$ & $10.10 \pm 0.56$ & \multirow{2}{*}{$5.59 \pm 0.54$} & \multirow{2}{*}{8.16} \\
\hline & 10 & $0.334 \pm 0.101$ & $12.52 \pm 1.02$ & & \\
\hline \multirow{2}{*}{\begin{tabular}{|c|} 
Named after S.M.Kirov \\
$\left(h_{10}{ }^{8}, V^{d a f}=8.0 \%\right)$
\end{tabular}} & 0 & $0.520 \pm 0.055$ & $5.27 \pm 2.55$ & \multirow{2}{*}{$0.16 \pm 0.43$} & \multirow{2}{*}{0.96} \\
\hline & 10 & $0.548 \pm 0.004$ & $7.49 \pm 0.49$ & & \\
\hline \multicolumn{6}{|c|}{ Inertinite concentrate } \\
\hline \multirow{2}{*}{$\begin{array}{c}\text { Blahodatna } \\
\left(c_{5}, V^{d a f}=46.12 \%\right)\end{array}$} & 0 & $0.090 \pm 0.002$ & $19.59 \pm 0.84$ & \multirow{2}{*}{$7.98 \pm 0.64$} & \multirow{2}{*}{5.28} \\
\hline & 10 & $0.092 \pm 0.010$ & $22.31 \pm 0.54$ & & \\
\hline \multirow{2}{*}{$\begin{array}{c}\text { Yuvileina } \\
\left(c_{6}, V^{d a f}=42.24 \%\right) \\
\end{array}$} & 0 & $0.110 \pm 0.003$ & $14.47 \pm 0.01$ & \multirow{2}{*}{$7.35 \pm 0.17$} & \multirow{2}{*}{4.32} \\
\hline & 10 & $0.116 \pm 0.008$ & $17.65 \pm 1.11$ & & \\
\hline \multirow{2}{*}{$\begin{array}{l}\text { Krasnolymanska } \\
\left(l_{3}, V^{\text {daf }}=31.9 \%\right)\end{array}$} & 0 & $0.180 \pm 0.012$ & $3.57 \pm 0.24$ & \multirow{2}{*}{$2.22 \pm 1.43$} & 264 \\
\hline & 10 & $0.209 \pm 0.015$ & $2.49 \pm 0.50$ & & 2.04 \\
\hline Named after & 0 & $0.222 \pm 0.003$ & $4.71 \pm 0.24$ & & \\
\hline $\begin{array}{c}\text { O.F. Zasiadko } \\
\left(m_{3}, V^{d a f}=31.29 \%\right)\end{array}$ & 10 & $0.225 \pm 0.027$ & $7.13 \pm 6.69$ & $5.08 \pm 2.83$ & 3.12 \\
\hline Krasnoarmiiska-Zah. & 0 & $0.223 \pm 0.002$ & $3.14 \pm 0.18$ & $1.36 \pm 0.35$ & 1.68 \\
\hline & 10 & $0.253 \pm 0.001$ & $2.27 \pm 0.06$ & & \\
\hline Yasynovska-Hlyboka & 0 & $0.283 \pm 0.004$ & $2.99 \pm 0.47$ & $670+102$ & 264 \\
\hline$\left(m_{3}, V^{d a f}=19.6 \%\right)$ & 10 & $0.250 \pm 0.006$ & $14.24 \pm 0.57$ & $0.10 \pm 1.02$ & 2.04 \\
\hline Named after S.M. Kirov & 0 & $0.606 \pm 0.015$ & $4.96 \pm 0.30$ & $0.35 \pm 0.38$ & 0.72 \\
\hline$\left(h_{10}{ }^{6}, V^{d a f}=8.0 \%\right)$ & 10 & $0.582 \pm 0.013$ & $5.06 \pm 1.51$ & & \\
\hline
\end{tabular}

Shift amounts, measured directly under pressure, can significantly exceed the obtained values. Considering the number and variety of bonds in the macromolecule of coal, the energy accumulated in the form of such structural stresses is comparable to the activation energy of free-radical reactions $(5-25 \mathrm{~kJ} / \mathrm{mol})$ [2]. The results show that the effect of the frequency shift of the absorption bands is due to the mechanical deformation of the valence bonds, which are part of the macromolecule.

The recorded effects in the growth of the coal substance aromaticity degree, the shift of the absorption bands, and the redistribution of hydrogen are statistically valid $(p<0.05)$ for 
coals throughout the metamorphism series, and are stable over time.

Research of the restructuring processes in the molecular structure of coal using FTIR method with a change in temperature showed that when heating in the spectrum of vitrinite there are more powerful changes than in the spectrum of inertinite. Moreover, all structural indexes for vitrinite statistically valid change with increase in the temperature. At the same time, no significant changes were recorded for inertinite.

Structural indexes, recorded by the electron paramagnetic resonance (EPR) method, with a rise in temperature, statistically valid change for both macerals. Figure 2 shows the EPR spectrum of inertinite concentrate at $20^{\circ} \mathrm{C}$ and at $45^{\circ} \mathrm{C}$, which illustrates the typical effect of heat flux on the electronic structure of the coal macerals. The effect of changing the waveform of inertinite during heating is reversible in a small temperature range. The absorption process of electromagnetic energy is of physical nature since, firstly, after cooling, the spectrum parameters take on initial values, secondly, the area under the curve does not change, which proves the absence of chemical transformations. The narrowing of the EPR spectrum means the enhancement of the exchange interaction between the conjugation systems, that is, the accumulation of energy in the molecular structure of the coal substance. In a specific example, a sample of inertinite, weight $10 \mathrm{mg}$, accumulated in the form of structural stresses $\approx 5 \cdot 10^{-7} \mathrm{~J}$. Given that the macromolecule of coal can have tens of thousands of atoms, in terms of mole, this is $\mathrm{kJ}$, which is comparable to the activation energy of free-radical reactions.

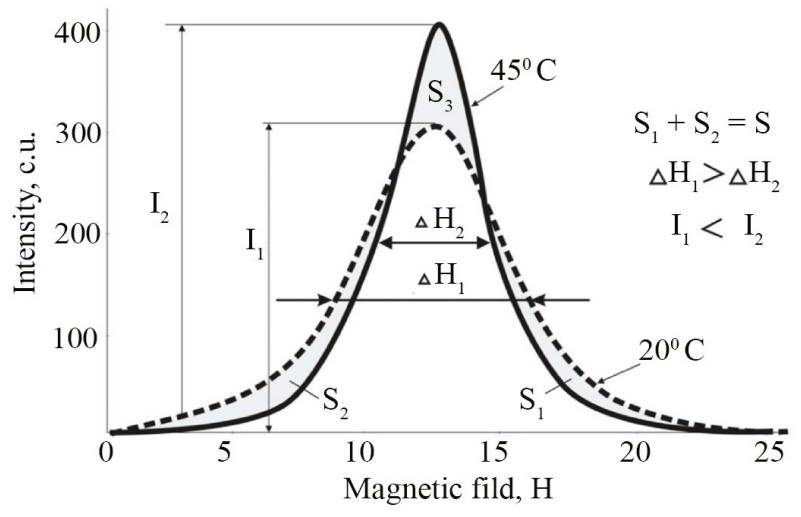

Fig. 2. Temperature dynamics of EPR spectrum in the inertinite.

Thus, the authors experimentally proved the ability of the coal substance to accumulate thermal and mechanical energy in the form of structural stresses in an amount sufficient to activate free-radical reactions. Analogically, the total energy accumulated in polymers [3] in the form of structural stresses affects the further transformations in the substance, reducing the energy barriers of their activation.

The presence of paramagnetic centers in the coal substance in the amount of $\approx n \cdot 10^{19} \mathrm{~g}^{-1}$ and the low activation energy of free-radical reactions compared with similar chemical 5$25 \mathrm{~kJ} / \mathrm{mol}$ against $200-300 \mathrm{~kJ} / \mathrm{mol}$ suggests that the most likely mechanism of structural transformations in Charcoal with the release of fluids are free-radical reactions. Most of the free radical reactions lead to the separation of stable low molecular weight compounds and the preservation of the free radical, which provides a chain course of reactions.

\section{Physical-chemical model}

In modern conditions, the coal-bearing massif of Donbas is a complex of terrigenous rocks, including low-thickness coal beds. Small in power natural tectonic processes and stable 
temperature conditions allow suggesting that in regional terms coal beds in an undisturbed massif are in a state close to equilibrium. At the same time, individual components of the organic one of beds are in a metastable state with a low energy barrier in the activation of structural transformations. Based on the obtained experimental data, a phenomenological model of physical-chemical structural transformations of a metastable coal substance is proposed. (Fig. 3).

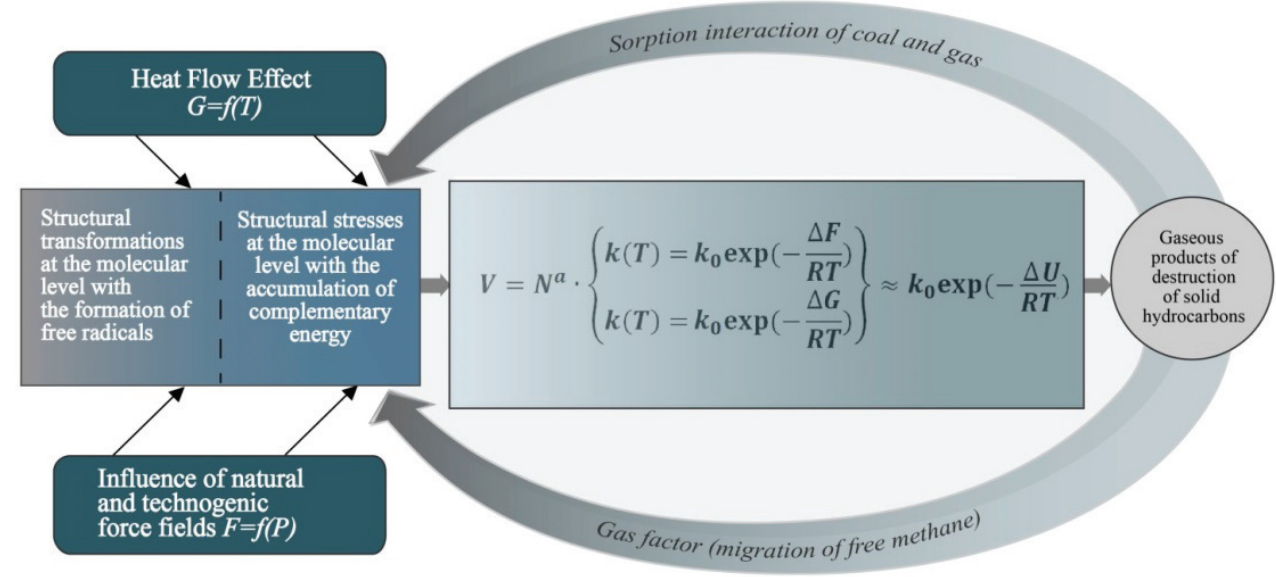

Fig. 3. Phenomenological model of physico-chemical structural transformations of a metastable coal substance: $N^{a}$ - concentration of active centers; $k$ - the reaction rate constant, $\mathrm{c}^{-1} ; k_{0}$ - the preexponential factor; $\Delta U$ - the change in the elastic energy accumulated under the influence of external factors; $R$ - gas constant; $T$ - temperature, $\mathrm{K}$.

The essence of this model lies in the fact that under the influence of environmental loads in coal simultaneously with structural transformations at the molecular level with the formation of free radicals energy is accumulated in the form of structural stresses. This additional energy is released by the system in the process of stress relaxation according to a free-radical mechanism with the emission of gaseous products in the solid coal phase destruction. At the same time, gases formed as a result of transformations affect the state of substance and, accordingly, the kinetics of the processes.

Free-radical processes are related to processes with an active complex, the velocity of which $(V)$ is proportional to the concentration of active $\mathrm{Na}$ centers, which are free radicals in the coal. The expression for the velocity of free-radical reactions is:

$$
V=N^{a} \cdot k,
$$

where $k$ - process velocity constant.

The velocity constant of a destructive free radical reaction (1) can be calculated by statistical thermodynamic methods using standard thermodynamic functions - the Gibbs energy $(\mathrm{G})$ and the Helmholtz energy $(\mathrm{F})$. The formulas that determine the velocity constant of free-radical reactions include both temperature and energy, accumulated as stresses in the molecular structure of a substance. Consequently, relaxational free-radical processes in the molecular structure of carbonated organics take place both with an increase in temperature and with a change in the force load. Accordingly, the constant velocity of a free-radical reaction is proportional to the change in the elastic energy accumulated in the molecular structure of the coal substance and is determined by the equation:

$$
k=k_{0} e^{(-\Delta U / R T)}
$$

Equation (2) is obtained for polymers [3] and can be applied to coal, which can be 
considered as a copolymer.

It follows from the model that the methane release process, under the conditions of a gas-saturated coal and rock massif under the action of constant geomechanical factors, is permanent, that is, it occurs constantly, during the geological development of a coal deposit, but with different intensity.

The proposed physic-chemical model is based on the genetic connection of coal methane with fossil organic matter and determines the conditions for the activation of structural transformations in coal mines. The model predicts structural transformations leading to gas generation and describes possible options for the development of the coal-gas system in contrmporary conditions.

The physical-chemical model of methane release reflects the connection of processes at the molecular level with the macro level, that is, with the processes in the coal-rock massif and is coherent with the previously established in Institute of Geotechnical Mechanics named by N. Poljakov of National Academy of Sciences of Ukraine regularity of rock destruction by weak impact [4]. Removing the load, that is, "weak influence" causes energy-beneficial, relaxation structural transformations: conformational transitions, migration of free radicals, intramolecular redistribution of protons, which can lead to the elimination of stable low-molecular compounds by a free-radical mechanism.

The proposed physico-chemical model explains the formation of a metastable singlephase system of the "solid solution" type. The separated gas molecules are in the absorbed state inside the defects of the molecular structure, formed under the action of geomechanical forces. If, as a result of the relaxation of structural stresses in the organic substance of coal such a molecule is initially was formed on the surface or of a pore or crack, then it will be in the adsorbed state until the pressure decreases moment and the transition to the free state.

\section{Conclusions}

The accumulation of heat and mechanical energy by coal in the form of structural stresses in an amount sufficient to activate free-radical reactions was experimentally recorded. Relaxation of the accumulated energy in a gas-saturated coal-bearing massif can lead to the generation of methane by coal.

It was established that gas generation in the process of coalification, in its essence, is the energy response of the system to the action of external geomechanical factors (temperature and pressure), that is, the release of accumulated additional energy with the release of gaseous products of destruction of the solid phase of organic substance of coal.

A model of physical-chemical transformations of a coal substance with the release of fluids is proposed and it is proved that in modern conditions in an undisturbed coal-rock massif the processes can be relaxation in nature.

\section{References}

1. E.V. Ul'yanova, O.N. Malinnikova, A.V. Burchak, A.K. Balalaev, V.I. Baranovsky, J. Mining Sci., 53, 8 (2018)

2. D.C. Nonhebel and J.C. Walton, Free-Radical Chemistry: Structure and Mechanism (Cambridge University Press, 1974)

3. P.Yu. Butyagin and A.N. Streletskii, Phys. Solid State, 47, 7 (2005)

4. Poturaev, V.N., Zorin, A.N., Vinogradov, V.V., Bulat, A.F. (1995). Zakonomernost razrusheniya predelno napryazhennykh gornykh porod pri slabykh vozdeystviyakh. Nauchnye otkrytiya. Diplom \#1. Moskva 